\title{
Powers as the Fundamental Entities in Philolaus' Ontology ${ }^{1}$
}

\author{
Irini - Fotini Viltanioti
}

The main claim of this paper is that powers are the fundamental entities in Philolaus' ontology. Limiters $(\pi \varepsilon \rho \alpha i v o v \tau \alpha)$ and unlimiteds ( $\alpha \pi \varepsilon \varphi \rho \alpha)$ are to be respectively understood as the power to limit and the power to be limited. As powers to do something, limiters and unlimiteds are different from their individual bearers, namely the "things that are" ( $\dot{\varepsilon} \delta \tau \tau \alpha)$. Number or harmony, that is the power to fit together, makes, along with the basic powers to limit and to be limited, things what they are. Philolaus' vv́бı should be understood as the outcome of the working of the three other powers, namely $\pi \varepsilon \rho \alpha i v o v \tau \alpha$, $\alpha \epsilon \varepsilon i \rho \alpha$ and $\alpha \rho \mu o v i ́ \alpha$, coming together and coming to be realized ( $\left.\dot{\alpha} \rho \mu{ }^{\prime} \chi \theta \eta\right)$. In other words, $\varphi v ́ \sigma ı \varsigma$ is the state that results from the realization of the three fundamental powers. Philolaus' $\dot{\varepsilon}$ óv $\tau \alpha$ are to be considered as coming out of the four primary

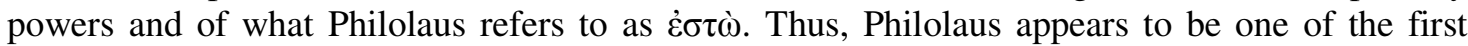
power structuralists.

\section{Introduction}

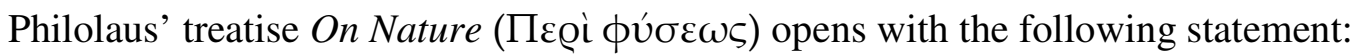

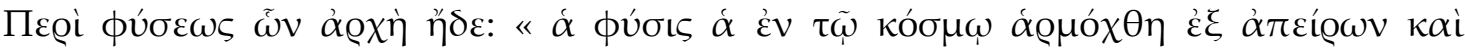

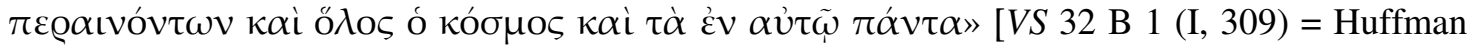
$93 \mathrm{ff}$.

On Nature, of which this is the beginning: "Nature in the world-order was fitted together out of unlimiteds and limiters, both the whole world-order and all the things in it" 2 .

\footnotetext{
${ }^{1}$ Earlier versions of this paper were presented at the Work in Progress seminar of the "Power Structuralism in Ancient Ontologies" project, directed by Dr Anna Marmodoro and supported by the European Research Council, at the University of Oxford. I am very grateful to Anna Marmodoro and Brian Prince for comments. I also thank Simone Seminara. My participation in the Project was supported by the FRS - FNRS and by a scholarship of the Philippe Wiener Maurice Anspach Foundation.
} 
Journal of Ancient Philosophy Vol. VI 2012 Issue 2

It is clear from the fragment above that Philolaus takes limiters and unlimiteds to be the fundamental items in his ontology, that out of which everything else is "fitted together". But it is far from clear what Philolaus means by limiters and unlimiteds, for he does not offer an explicit explanation in the extant fragments. This poses a difficult and exciting interpretative challenge to classical scholars. Many interpretations have been recently put forward concerning the nature of Philolaic Principles. In what follows, I shall first give a brief survey of the interpretations already existing in the literature and raise some of the difficulties they face. In the second part of the paper, I shall argue for an alternative account of Philolaus' position, which, as I endeavor to show, is well grounded in the extant texts and brings out the originality of the metaphysical position Philolaus is putting forward.

\section{The state of art with respect to understanding limiters and unlimiteds}

I shall here below examine the main received interpretations of the opening lines of Philolaus' book On Nature ${ }^{3}$.

Boeckh identifies the "limit" with the One and the "unlimited" with the Indefinite Dyad $^{4}$. From this identification of the basic principles of Philolaus' and Plato's ontology, it supposedly follows that we can understand Philolaus' position along the same lines on which we understand Plato's position. But it is far from uncontroversial that Plato relied on the One and the Indefinite Dyad to account for all there is in his ontology. Secondly, even if we granted that Plato did have this account of reality based on the One and the

\footnotetext{
${ }^{2}$ My translation, based upon Huffman's translation with some changes.

${ }^{3}$ As to whether Philolaus himself gave his book the title On Nature or not, see Huffman, Carl. Philolaus of Croton. Pythagorean and Presocratic. A commentary on the fragments and testimonia with interpretative essays (Cambridge: Cambridge University Press, 1993), pp. 94 95.

${ }^{4}$ Boeckh, August. Philolaos des Pythagoreers Lehren nebst den Bruchstucken seines Werkes (Berlin, 1819), pp.54 ff.
} 
Journal of Ancient Philosophy Vol. VI 2012 Issue 2

Dyad, there is much controversy about how to understand it; thus, how can we be expected to lean on our understanding of Plato to understand Philolaus? Thirdly, on Boeckh's suggested reading, the specifity of Philolaus' thought disappears, as it turns out to be very much aligned to Plato's thought; and this seems at least anachronistic. Finally, Philolaus does not speak of the "limit" and of the "unlimited", but of "limiters" and "unlimiteds". Boeckh's interpretation did not receive wide support among modern commentators.

Arguing that Philolaus assumes the acquaintance of his readers with Pythagorean number doctrine, Schofield ${ }^{5}$ suggests that limiters and unlimiteds are to be respectively understood as odd and even numbers. He finds support for this thesis in two surviving fragments of Philolaus explicitly dealing with number ${ }^{6}$. But, as Huffman ${ }^{7}$ correctly points out, Schofield's interpretation does not work very well for two reasons. Firstly, if limiters and unlimiteds were to be simply identified with numbers, there would have been no reason for Philolaus to introduce them over and above numbers - or at least, if there were a reason, it remains mysterious to us. In addition, the extant texts seem to distinguish (rather than identify) odd and even numbers from limiters and unlimiteds, for the latter are never mentioned in the same proposition as the former.

According to Burkert, limiters and unlimiteds correspond to material atoms and the empty interstices between atoms; he writes:

"If the $\ddot{\alpha} \pi \varepsilon\llcorner\varrho \alpha \pi \varrho \alpha \gamma \gamma \mu \alpha \tau \alpha$ are thought of in the context of endless divisibility, the plural is

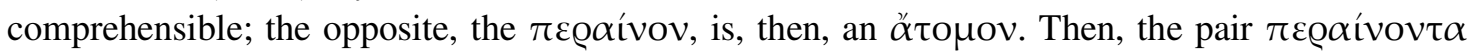

\footnotetext{
${ }^{5}$ Kirk, Geoffrey Stephen and Raven, John Earle, The Presocratic Philosophers, (Cambridge, Cambridge University Press, 1957); $2^{\text {nd }}$ ed. revised by Schofield, Malcolm (Cambridge: Cambridge University Press, 1983), p. 326.

${ }^{6}$ Infra and n. 39 .

${ }^{7}$ Huffman (1993), p. 48.
} 
Journal of Ancient Philosophy Vol. VI 2012 Issue 2

and $\alpha \dot{\pi} \pi \varepsilon\llcorner\alpha$, both of which are called $\dot{\varepsilon}$ óv $\tau \alpha$, would correspond to the Leucippan $\delta \dot{\varepsilon} \nu$ and $\mu \eta \delta \varepsilon ́ v$ - material atoms and the "empty" interstices, which do yet "exist" 8 .

This interpretive hypothesis is based upon the few connections the ancient tradition makes between Pythagoreans and Atomists ${ }^{9}$. Burkert, however, does not develop it further, and the textual basis for it appears, at best, tenuous.

Following Raven ${ }^{10}$, Guthrie ${ }^{11}$ takes the limit and the unlimited to be the basic principles of number:

"The elements of numbers are, ultimately, the limit and the unlimited, and secondarily, the odd and the even and the unit. [...]. Limit and the unlimited are the ultimate notions, as being wider genera within which fall the odd and the even" ${ }^{12}$.

This interpretation is supposed to be helpful to understand Philolaus. However, Guthrie speaks of the limit and of the unlimited, not of Philolaus' limiters and unlimiteds. His interpretation is exclusively based upon the Aristotelian account of the Pythagoreans, which assigns the primary role to number. When he refers to the "limit" and to the "unlimited", Guthrie does not refer at all to Philolaus' fragments. And, when he refers to Philolaus ${ }^{13}$, he does not mention limiters and unlimiteds and does not refer to the extant fragments. Furthermore, on Guthrie's suggested reading, number becomes the centre of Philolaus' doctrine, while limiters and unlimiteds are reduced to principles of number. Thus, limiters and unlimiteds do not explain anything which odd and even number could

${ }^{8}$ Burkert, Walter. Lore and Science in Ancient Pythagoreanism (Cambridge, Mass, 1972); English translation of: Weisheit und Wissenschaft: Studien zu Pythagoras, Philolaos und Platon (Nurenmberg, 1962), pp. $258-259$.

${ }^{9}$ For example Aristotle, De anima, I 404 a 1 ff.; Diogenes Laertius, 9, 38; Iamblichus, De vita Pythagorica, 104.

${ }^{10}$ Raven, John Earle. Pythagoreans and Eleatics (Cambridge, Cambridge University Press, 1948).

${ }^{11}$ Guthrie, William Keith Chambers. A History of Greek Philosophy (Cambridge, 1962), pp. 240 ff.

${ }^{12}$ Ibid., pp. $240-242$.

${ }^{13}$ Ibid., pp. $329-333$. 
Journal of Ancient Philosophy Vol. VI 2012 Issue 2

not explain. This does not agree with the existent fragments, which make clear that limiters and unlimiteds are the fundamental items in Philolaus' ontology.

Barnes thinks that limiters are shapes (pre-eminently geometrical shapes) and unlimiteds are stuffs of various kinds:

"To apply a limiter to an unlimited is to give specific shape or form to a mass or unformed stuff. [...] A potter moulds a wedge of clay into a pot; a sculptor casts a mass of bronze into a statue; a baker pats his dough into a loaf; a carpenter shapes a table from rough timber: all these artists apply a shape to stuff, a limiter to an unlimited. Shapes are essentially limiting: anything shaped in such and such a way has, eo ipso, limits beyond which it does not extend; it is determined and circumscribed by its shapely boundaries. Stuffs, on the contrary, are essentially unlimited; clay and bronze; dough and wood, have no shapes" 14 .

According to Barnes, Philolaus is thus anticipating in some ways the Aristotelian distinction between matter and form. Standing in strong contrast with the Pre- Socratic tradition, Philolaus focuses not only on matter, as the Pre-Socratics did, but also on shapes, that is form:

"His fundamental tenet, [...], is that both matter and form are required in any analysis or explanation of the phenomena: we have to account not only for the diverse materials present in the mundane world, but also for the diverse ways in which those materials present themselves to us: we live in a material world, but the material is informed" 15 .

However, this interpretation is based upon Aristotle's reading on the Pre-Socratics and the Pythagoreans. Beyond Aristotle's account, Barnes does not put forward any argument based on Philolaus' own fragments and directly transmitted views.

Arguing that Philolaus' ontology is based on an analysis of the presuppositions of cognition, Hussey considers that limiters are simply "things which bound" and unlimiters “things that are unbounded". In addition, Hussey shares Barnes' matter and form reading:

"Philolaus' careful attempt to build up a general ontology on the basis of an analysis of ordinary cognition, guided by mathematics, leads him naturally in the direction of Aristotelian "form" and "matter". Whatever stuff an individual is thought of as being "made of", is in itself not

\footnotetext{
${ }^{14}$ Barnes, Jonathan. The Presocratic Philosophers (London, 1979), p. 86.

${ }^{15}$ Ibid., pp. 87.
} 
Journal of Ancient Philosophy Vol. VI 2012 Issue 2

"bounded"; for it might be present in any quantity. But for there to be an individual, there must be also a "bound" 16 .

Nevertheless, Hussey's suggested reading suffers from the same problems as Barnes'. Firstly, it is not quite clear which ontological groups are represented by "things which bound" and "things that are unbounded". Secondly, the distinction between matter and form seems anachronistically attributed to Philolaus.

Finally, Huffman suggests that the terms limiters and unlimiteds have to be understood within the context of Pre-Socratic philosophy and, more specifically as in engagement with other thinkers of the time, such as Parmenides and Anaxagoras, rather than within the framework of Pythagorean esoteric doctrine. Huffman's own interpretation is that the unlimiteds are a continuum without boundaries, while limiters are what provide boundaries of some sort in this boundaryless continuum. He also draws attention to the fact that limiters and unlimited would have never come together to form the world-order unless a third principle, namely $\alpha \rho \mu$ ovía, had supervened to bind them together ${ }^{17}$. This interpretation is prima facie more compelling than the others I have examined so far. Nevertheless, it encounters some serious difficulties, which I shall bring out in the following section.

\section{The fundamental level of reality according to Philolaus}

In the previous section, I discussed modern scholarship from the point of view of Philolaus' philosophy in general. In this section, I shall examine a crucial interpretative issue for understanding Philolaus' metaphysics, namely: what does he think there is at the fundamental level of reality? In other words, I shall be concerned with the specific

\footnotetext{
${ }^{16}$ Hussey, Edward. "Pythagoreans and Eleatics", in Taylor, Christopher (ed.). From the Beginning to Plato, Routledge History of Philosophy I (London and New York, 1997), 161.

${ }^{17}$ Huffman (1993), pp. $37-53$.
} 
Journal of Ancient Philosophy Vol. VI 2012 Issue 2

question whether limiters and unlimiteds are to be essentially understood as things doing something or as powers to do something. First, I shall discuss what recent scholars think in this regard. Second, I shall describe my own hypothesis, and then examine, in the following section, what Philolaus tells us about limiters and unlimiteds, on one hand, and

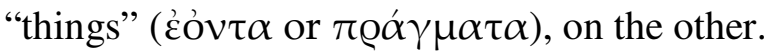

The majority of scholars see limiters and unlimiteds to be stuffs or things or, at least, inseparable from things. Burkert, for example, argues that

"Limit and unlimitedness are not isolated as entities in themselves, congealed into an abstract substantive or hypostasized as intangible substance, but they are thought of as scattered or deployed, so to speak, in individual things, $\pi \varepsilon \varrho \alpha$ ívov $\tau \alpha$ or $\alpha$ $\pi \varepsilon\llcorner\varrho \alpha " 18$.

Following Cherniss ${ }^{19}$, Burkert justifies this view by explaining that a Pre-Socratic thinker does not separate things and their qualities, such as "warm" and "cold". According to Burkert, by such words, a Pre-Socratic means the sum of particular things characterized by the word rather than an abstract quality. It is only through the Platonic dialectic method that qualities and quantities can be thought as separated from objects. Thus, Burkert thinks that there cannot be any separation even in thought between things and their qualities, such as "limiting" or "unlimited", even if the Philolaic division is certainly more abstract than an analysis in terms like "warm" and "cold". However, as I shall argue in the following section, Philolaus' text does appear to support the idea of a clear distinction between limiters and unlimiteds, on one hand, and the unique individual things, which are qualified as limiting or unlimited or both limiting and unlimited, on the other $^{20}$.

\footnotetext{
${ }^{18}$ Burkert (1972), p. 254.

${ }^{19}$ Cherniss, Harold. Aristotle's Criticism of Presocratic Philosophy (Baltimore: John Kopkins Press, 1935; repr.: New York: Octagon, 1964, pp. 375 ff.; Idem. "The Characteristics and Effects of Presocratic Philosophy", Journal of the History of Ideas, 1951, 12, pp. $342 \mathrm{ff}$.

${ }^{20}$ I cannot engage, within the limits of this paper, in a general survey of whether what Burkert says is true of all Pre-Socratics, or even of some of them. I am thus limiting myself only to the evidence we have of how Philolaus thought.
} 
Journal of Ancient Philosophy Vol. VI 2012 Issue 2

In a comparable way, as mentioned above, Barnes intends limiters to be shapes and unlimiteds to be stuffs, such as oil or vinegar, even if, unlike Burkert, he assumes that, by the limiters-unlimiteds division, Philolaus approaches the Aristotelian distinction between form and matter. Nevertheless, it is far from clear what ontological groups such as "shapes" and "stuffs" exactly are. In other words, "shapes" and "stuffs" do not reach the level of clarity needed for ontological categories.

According to Huffman, limiters and unlimiteds "are not treated [by Philolaus] as abstract principles divorced from the world, but rather as manifest features of the world"21. On Huffman's suggestion, the spherical shape of the cosmos and the properties of the sphere including the notion of a center, the stops on a string, the process or desire or action of breathing and intellectual activity, are all examples of limiters. In all these cases, the limiters are what provide boundaries to an undefined and boundaryless continuum. On the other hand, stuffs, such as fire or air, qualities, such as "hot", things like a string and the undefined continuum of possible musical pitches it can produce, or other continua, such as that of the void, time and sound, should be understood as examples of unlimiteds. For example, the human embryo is composed when the process of breathing, which is a limiter, limits the hot considered as an unlimited continuum. The pitches on a string are another example:

"If we think in terms of a monochord for illustration [...], the string and the indefinite number of pitches it can produce can be compared to the unlimited, while stops placed along it to determine specific pitches are the limiters" 22 .

Thus, it appears that, on Huffman's reading, shapes and stuffs are good examples of limiters and unlimiteds, even if they are not identified with limiters and unlimited, as Barnes proposes. I submit Huffman's interpretation has however the following weakness:

\footnotetext{
${ }^{21}$ Huffman (1993), p. 40.

${ }^{22}$ Ibid. 44. As Huffman notes, this example shows that limiters and unlimiteds alone cannot produce an ordered system. Harmonia is needed to produce not just any set of pitches, but "a pleasing set of limits in the unlimited in accordance with number"; ibid., pp. 45. I shall come back to the topic of harmonia in a later section of the paper.
} 
Journal of Ancient Philosophy Vol. VI 2012 Issue 2

On his account, items of entirely different nature, from shape to particular activities and abstractions, are enumerated among limiters or unlimiteds. Huffman's interpretation makes the limiters and unlimiteds look like very odd ontological categories, and it is not clear what defines (and unifies) each. In addition to giving this reason for puzzlement, Huffman often refers to limiters and unlimiteds as "the basic elemental powers", equated to "things that are" $(\varepsilon \dot{v} \nu \tau \alpha)^{23}$. But what does it mean? No account or explanation of the use of the term "power" is given by Huffman. One is left wandering what limiters and unlimiteds ultimately are: are they features of things, shapes, actions, stuffs, particular things, qualities, powers or something else?

It is crucial to note that in the text there is no hint of limiters and unlimiteds being

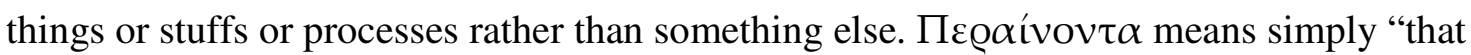
which limits", while $\alpha$ $\pi \varepsilon \iota \rho \alpha$ correspond to "that which are unlimited".

In what follows, I shall argue that $\pi \varepsilon \rho \alpha i ́ v o v \tau \alpha$ (limiters) and $\alpha$ $\pi \varepsilon\llcorner\varrho \alpha$ (unlimiteds) are to be essentially understood as powers to do something, namely the (active) power to limit and the (passive) power to be limited. Powers are generally understood as properties directed towards an end. They dispose their possessor to be or act in a specific way, which is manifested in appropriate circumstances (eg. something with the power to heat is disposed to heat something cooler $)^{24}$. As powers to do something, limiters and unlimiteds are different from their individual bearers, the "things that are" (ćóv $\tau \alpha$ ), for

\footnotetext{
${ }^{23}$ For example. see ibid., pp. $103 \mathrm{ff}$.

${ }^{24}$ I do not have enough space to discuss the metaphysics of powers more here. For further reading on powers metaphysics, see: Heil, John. From an Ontological Point of View (Oxford, Clarendon Press, 2003); Bird, Alexander. Nature's Metaphysicis: Laws and Properties (Oxford, Oxford University Press, 2007); Martin, Charles Burton. The Mind in Nature (Oxford, Oxford University Press, 2008); Marmodoro, Anna. "Do Powers Need Powers to Make Them Powerful? From Pandispositionalism to Aristotle", History of Philosophy Quaterly, 26, 2009, pp. 337 - 352; Mumford, Stephen. Dispositions (Oxford University Press, 1998); Mumford, Stephen and Anjum, Rani Lill. Getting Causes from Powers (Oxford, Oxford University Press, 2011); Choi, Sungho and Fara, Michael. Dispositions (The Stanford Encyclopedia of Philosophy, 2012, http://plato.stanford.edu/entries/dispositions/).
} 
Journal of Ancient Philosophy Vol. VI 2012 Issue 2

example, this girl, this table, that tree, that animal etc., which have powers, or are the bearers of powers ${ }^{25}$. The fragment I shall examine in the following section traces clearly this distinction.

\section{Powers and "things that are"}

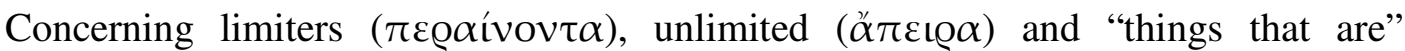

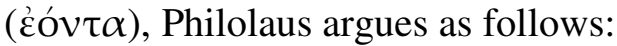

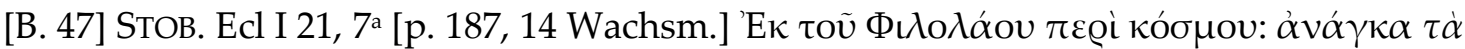

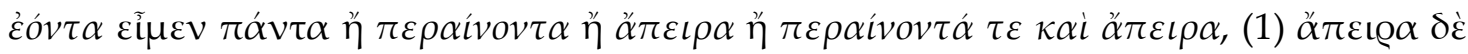

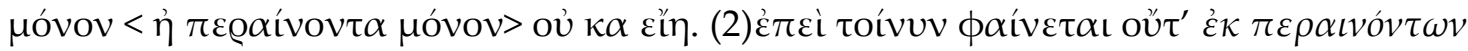

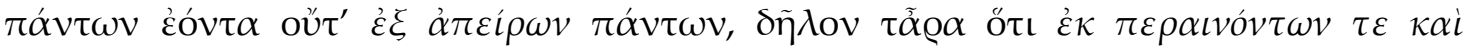

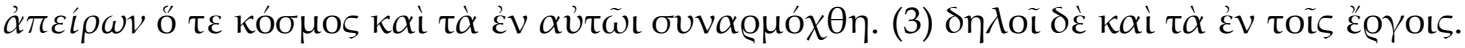

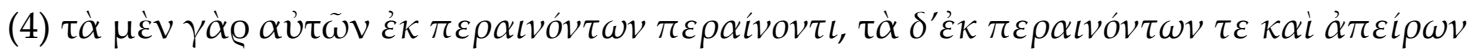

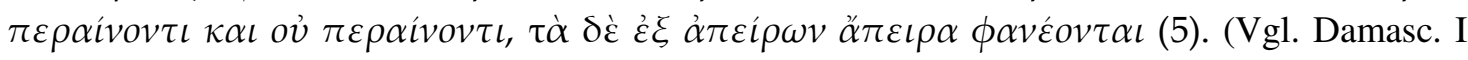

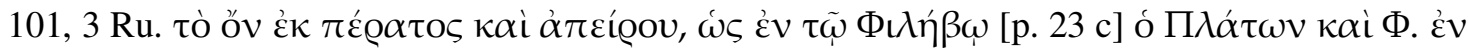

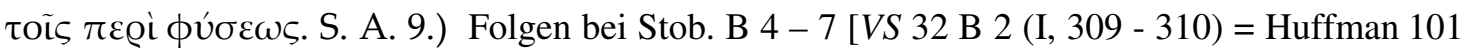
ff.; division and emphasis added] ${ }^{26}$.

This is one of the most interesting and yet difficult to understand of all the Philolaic fragments. The consensus among modern scholars is that the argument proceeds in an Eleatic manner, offering, in Nussbaum's words, "an exhaustive enumeration of possibilities and reaching the correct one by eliminating its rivals" ${ }^{27}$. On this reading, the fragment is usefully divided into five sentences. I retain here this traditional division.

\footnotetext{
${ }^{25}$ The plural form ( $\pi \varepsilon \rho \alpha i v o v \tau \alpha$, $\left.\alpha \varkappa \varepsilon i \rho \alpha\right)$ could be explained by the fact that the powers to limit and to be limited are viewed in their relation to the individual bearers.

${ }^{26}$ I shall propose a new translation of the fragment in what follows.

${ }^{27}$ Nussbaum, Martha. "Eleatic conventionalism and Philolaus on the conditions of thought", Harvard Studies in Classical Philology, 83, 1979, p. 97. See also Boeckh (1819), pp. 47 - 50; Burkert (1972), pp. 259 - 260; Barnes (1979), p. 386;Huffman (1993), p. 102.
} 
Journal of Ancient Philosophy Vol. VI 2012 Issue 2

However, as Huffman ${ }^{28}$ points out, there are several difficulties with the received interpretation of the fragment.

In this section of the paper, I shall first discuss these difficulties as well as the ones raised by the interpretation proposed by Huffman. Secondly, I shall offer an alternative reading, which is well supported by the Greek, and provides a more plausible and sophisticated explanation of what Philolaus wrote. This reading is more natural, allows a better understanding of the passage and avoids making Philolaus contradict himself. My assumption is that, if the Greek allows for more than one reading, then it is only fair to attribute to Philolaus the most sophisticated view of those that the texts support.

It is generally agreed that the first sentence of the fragment quoted above lists three possibilities: things are either all limiting, or all unlimited, or all both limiting and unlimited. In the second sentence, two of these possibilities, namely that things are either all limiting or all unlimited, are ruled out. The third sentence states the conclusion, namely that the world and everything in it were the result of harmonic composition of both limiting things and unlimited things. Sentences 4 and 5 are supposed to offer further support to the conclusion (sentence 3), by putting forward an argument based on facts or experience.

Yet, the second sentence, as we have it in the manuscripts, only eliminates one possibility, namely that things are unlimited alone. In order to eliminate the opposite

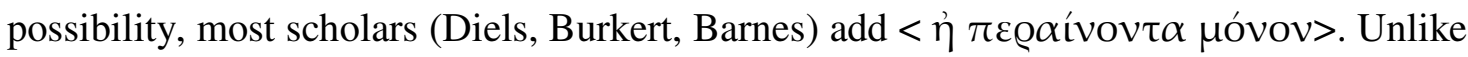
Huffman, I agree with this addition, and also with Nussbaum's suggestion that

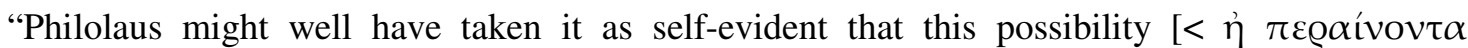
Hóvov>] is ruled out: the perainon implies the existence of that which gets bounded" 29 .

\footnotetext{
${ }^{28}$ Ibid. 102.

${ }^{29}$ Nussbaum (1979), p. 98.
} 
Journal of Ancient Philosophy Vol. VI 2012 Issue 2

Further, sentence 3 appears to be a repetition of what has been a bald statement ruling out two possibilities in sentence 2 . A serious difficulty arises from the fact that the standard interpretation seems to disregard the apparent difference of meaning between things being limiting, unlimited or both limiting and unlimited, on one hand (sentence 1), and things being from limiters, unlimiteds or both limiters and unlimiteds (sentence 3 ). These two statements are obviously not equivalent. Finally, the argument in sentences 4 and 5 has not been convincingly shown to support the conclusion in sentence 3. Far from this, it appears to come into contrast with this conclusion: the first three sentences are supposed to conclude that all things are both limiting and unlimited, but sentence 5 seems to recognizes things that are composed of limiting constituents and things that are composed of unlimited constituents.

Faced with these difficulties and incoherencies, Huffman proposes an alternative interpretation. I find myself to be in agreement with some of his suggestions, but in fact in disagreement with most of them, as well as with his final account. Before proposing my own interpretation, I shall discuss some of Huffman's claims.

Firstly, Huffman claims that

"When Philolaus refers to the "things that are" ( $\tau \dot{\alpha} \dot{\varepsilon}$ ḱv $\tau \alpha)$ in the first sentence, he has in mind a very restricted class of things, i.e. the basic elemental powers in the world, and he is not referring to the very general class of all the unique individual things in the world (e.g. this tree, that man, this rock, etc.)" ${ }^{30}$.

I do not agree with this reading. On the contrary, I think it is clear that, in sentence 1 , as in sentence 2, Philolaus has in mind the unique individual things in the world, the "things that are" ( $\tau \dot{\alpha}$ ćóv $\tau \alpha)$ in the present time. There is no hint in the text that Philolaus has in mind "a very restricted class of things, i.e. the basic elemental

\footnotetext{
${ }^{30}$ Huffman (1993), 103.
} 
Journal of Ancient Philosophy Vol. VI 2012 Issue 2

powers in the world". The traditional interpretation is then correct, pace Huffman, when it suggests that the first sentence refers to the "things that are".

Secondly, Huffman understands sentence 2 as a pointed remark directed against some of Philolaus' predecessors, namely Anaximander, Anaximenes and Anaxagoras. This is because Huffman thinks that the emendation to the text $(<\dot{\eta} \pi \varepsilon \rho \alpha$ ívovt $\alpha$ Móvov>) proposed by most scholars is unnecessary. I do not agree with this. On the

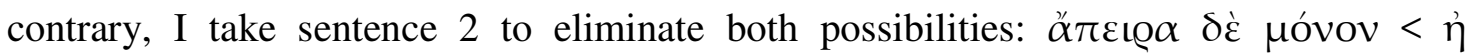

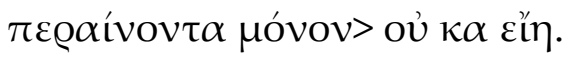

Next, I agree with Huffman's claim that the subject of sentence 3 "is no longer the elemental powers, but the world-order and the things in it" ${ }^{\prime 31}$. More precisely, I take

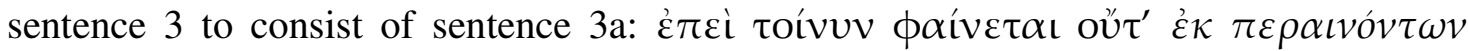

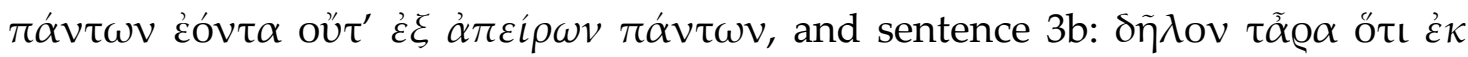

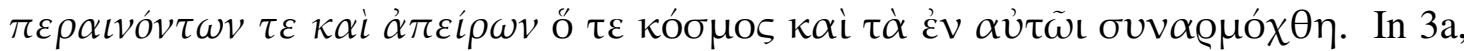

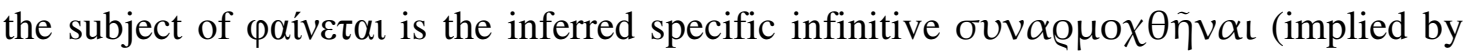

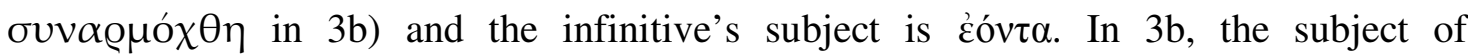

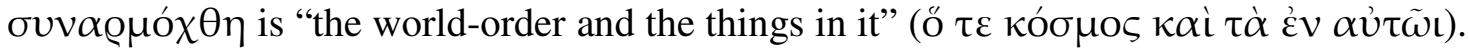
In my opinion, in sentence $3 \mathrm{a}$, Philolaus refers for the first time to the two principles, limiters and unlimiteds, concluding that the world and the things in it are fitted together from both limiters and unlimiteds.

In addition, as I shall explain in what follows, I agree with Huffman that the argument in sentences 4 and 5 "appeals once again to the evidence of individual things in the world in order to argue about the nature of the elemental powers", focusing on the way the "things that are" ( $\tau \dot{\alpha} \dot{\varepsilon} o ́ v \tau \alpha)$ act in the world.

${ }^{31}$ Ibid., pp. 104. 
Journal of Ancient Philosophy Vol. VI 2012 Issue 2

On the interpretation I want to put forward, the fragment enumerates three possibilities concerning the "things that are" (sentence 1 and 2) and justifies these possibilities by referring to the two principles, limiters and unlimiteds (sentence 3 ). Then, in sentences 4 and 5, it clarifies, first, the meaning of the three possibilities listed in sentences 1 and 2, and, second, the dependence between these three possibilities and the two principles mentioned in sentence 3 . He does so, by putting forward an argument based on experience about what the "things that are" ( $\tau \dot{\alpha}$ ḱóv $\tau \alpha)$ are capable of doing, i.e., what they have the power to do (ćo $\gamma \alpha)$.

In the light of these suggestions, I want to propose the following alternative translation of the fragment:

From Philolaus' On World: It is necessary that the things that are (in the present time) be all either limiting, or unlimited, or both limiting and unlimited, (1) but not in every case unlimited alone <or limited alone>. (2) Well then, since it is manifest that the things that are (in the present time) are neither from limiters alone, nor from unlimiteds alone, it is clear then that the world and the things in it were fitted together from both limiters and unlimiteds. (3) Their actions [the actions of the "things that are"] also make this clear. (4) For, some of them, out of limiters (or because of limiters), limit, others, out of limiters and unlimiteds (or because of limiters and unlimiteds) limit and do not limit, others, out of unlimiteds (or because of unlimiteds) appear unlimited. (5) (the being of limit and unlimited, as Plato in the Philebus and Philolaus in the On Nature [say] ${ }^{32}$.

In this fragment, as I understand it, Philolaus draws a distinction between the "things that are (in the present time)" and what they come from, namely the limiters and unlimiteds.

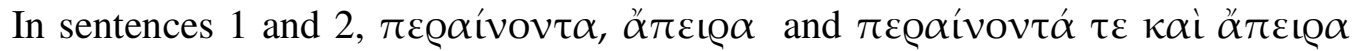
refer to the É $\cos _{\tau} \alpha$, understood as the "things that are (in the present time)", and not as "the basic elemental powers in the world", as Huffman thinks. The" things that are" (in the present time) are all either limiting, or unlimited, or both limiting and unlimited, but not in every case all unlimited alone <or limited alone>. As will be shown in sentence 5,

${ }^{32}$ Based upon Huffman's translation, with significant changes and emphasis added. 
Journal of Ancient Philosophy Vol. VI 2012 Issue 2

this suggests that the "things that are (in the present time)" have the power either to limit, or to be limited, or to both limit and be limited, but in no case have they all the power to be limited alone or all the power to limit alone (there are three possibilities of structural combination of the two primary entities).

In sentence 3, $\pi \varepsilon \varrho \alpha i ́ v o v \tau \alpha$ and $\ddot{\alpha} \pi \varepsilon\llcorner\alpha$ are the principles, which I propose to understand as the fundamental powers: limiters (the active power to limit) and unlimited (the passive power to be limited), which, together with harmony ( $\sigma v v \alpha \varrho \mu o ́ \chi \theta \eta)$, cause the origin of the world and of all that is in it. As it will be shown in sentence 5, these two principles are the origin of the three possibilities listed in sentence 1.

In sentence 4, I take Philolaus to be referring to what "things that are" do ( $\mathrm{\varepsilon} \varrho \gamma \alpha$ ), or, better, to what "things that are" ('́óv $\alpha \alpha$ ) are capable of doing, what they have the power to do. What the "things that are" do, or can do, depends on the powers they have, which in turn are ultimately grounded in the powers of limiting (limiters) and being limited (unlimiteds), out of which the "things that are" are constituted.

In sentence 5, we learn that, out of (or because of ${ }^{33}$ ) limiters (the power to limit)

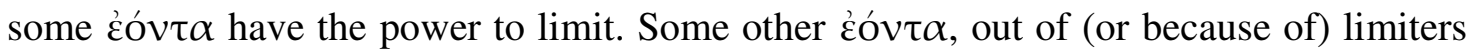
and unlimited (the powers to limit and to be limited), have the power to limit and be

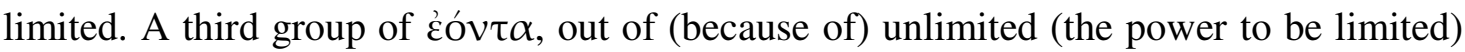
appear unlimited, having thus the power to be limited.

This assertion, as I understand it, means this: the ḱóv $\tau \alpha$ are fitted together from both limiters and unlimiteds, and not in any case from limiters alone or unlimiteds alone (sentence 3); thus, their power to limit, or to limit and be limited, or to be limited,

\footnotetext{
${ }^{33}$ The preposition $\dot{\varepsilon} \kappa$ (sentences 3 and 5) can bear various translations in English: out of, from (source); away from, from (separation); from, from [this point]...on (temporal); because of (cause); of (partitive, i.e. substituting for a partitive genitive); by, from (means). While in sentence $3 \dot{\varepsilon} \kappa$ means clearly out of, from, in sentence 5 both meanings, out of and because of, are allowed by the Greek.
} 
Journal of Ancient Philosophy Vol. VI 2012 Issue 2

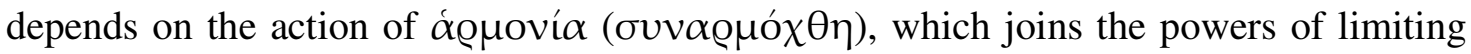
and being limited according to different proportions. That is, when, by proportion, the primary power of limiting (limiters) prevails over the primary power of being limited (unlimiteds), the غ̇òv is limiting ( $\pi \varepsilon \varrho \alpha i ́ v o v)$, which means it has the power to limit (rather than to be limited). And again, when, by proportion, the primary power to be limited (unlimiteds) prevails over the primary power to limit (limiters), the Ėov is unlimited (ăreıڤov), which means it has the power to be limited (rather than to limit). When, by proportion, the primary power to limit (limiters) is equivalent to the primary power to be limited (unlimited), then, the Ėov is both limiting and unlimited, which means it has the power to limit as well as to be limited.

Thus, the ever-realized powers (i.e. ever doing what they are in their nature capable of doing) of limiting ( $\pi \varepsilon \varrho \alpha i ́ v o v \tau \alpha)$ and being limited ( $\alpha$ $\pi \varepsilon\llcorner\varrho \alpha)$ ground the powers of the Éov $\tau \alpha$, which are powers that may or may not be realized, i.e., reach the end that defines their nature.

For example, unlike the primary powers to limit and to be limited, which are always doing what they are capable of doing, the power of the vase to limit water may or may not reach its end. That is, it may or may not be realized (e.g. when the water previously contained in the vase is poured on the table). In a similar way, the power of my blood to be limited by my body may or may not reach the end that defines its nature (e.g. in case of bleeding), and, again, the powers of water to be limited by the vase and to limit fire may or may not reach the end that defines its nature (e.g. when the water previously contained in the vase is poured over burning wood).

In this section, I have made reference only in passing to the role of $\alpha \varrho \mu$ oví $\alpha$, which is mentioned in B 1 together with pv́ఠıs, without offering any further explanation. In the next section, I shall be concerned with discussing the roles of $\alpha \varrho \mu o v i ́ \alpha$ and $\phi v ́ \sigma \iota \varsigma$ in Philolaus' ontology. 
Journal of Ancient Philosophy Vol. VI 2012 Issue 2

\section{Reinterpreting Philolaus' ontology}

In the following section, I shall argue that, for Philolaus, the most basic stratum of reality is four ever-realized powers, namely $\pi \varepsilon \varrho \alpha i ́ v o v \tau \alpha$ and $\alpha$ $\pi \varepsilon\llcorner\varrho \alpha$, as we have already seen, and, in addition to them, $\alpha \varrho \mu o v i ́ \alpha$ and $\phi \dot{\sigma} \sigma \varsigma$.

As explained above, $\pi \varepsilon \rho \alpha i ́ v o v \tau \alpha$ (limiters) and $\alpha$ $\pi \varepsilon \iota \varrho \alpha$ (unlimiteds) are to be respectively understood as the primary active power to limit and the primary passive power to be limited. Philolaus never attributes to them any property other than being capable of limiting and being limited. In other words, all there is to limiters and unlimiteds is respectively the power to limit and the power to be limited.

The powers to limit and to be limited are also fundamental. That is, they are not subjects of change and they are not constituted of any other elements as their building blocks. Fragments B 1 and B 2 attest that limiters and unlimited are the elements from which everything else is built.

If this is the nature of $\pi \varepsilon @ \alpha$ ívov $\tau \alpha$ (limiters) and $\alpha$ $\pi \varepsilon\llcorner\alpha$ (unlimiteds), what would then be the nature of $\alpha \varrho \mu$ oví $\alpha$ (harmony)?

As Huffman correctly emphasizes, in B 6 Philolaus argues that limiters and unlimiteds, being essentially unlike,

"would never come together to form an ordered whole unless some third principle bound them together. This principle is harmonia or "fitting together" ${ }^{34}$.

The following fragment attests that there is no relation between the essentially dissimilar power to limit (limiters) and the power to be limited (unlimiteds), for, if there were a relation, there would be no need for harmony to come upon them. Harmony only

\footnotetext{
${ }^{34}$ Huffman (1993), pp. 73.
} 
Journal of Ancient Philosophy Vol. VI 2012 Issue 2

joins together what is distinct ${ }^{35}$. In other words, limiters and unlimiteds are two unrelated powers, and it is only $\alpha \varrho \mu$ oví $\alpha$ that fits them together.

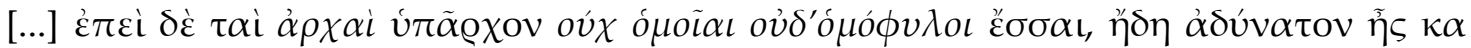

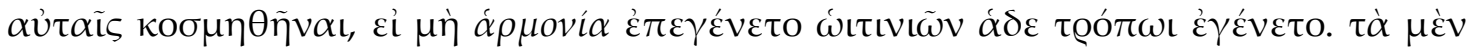

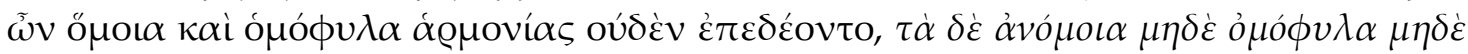

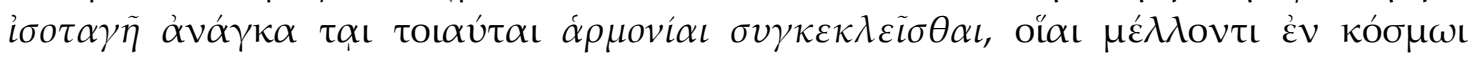
$\kappa \alpha \tau \varepsilon ́ \chi \varepsilon \sigma \theta \alpha \iota$ [VS 32 B 6 (I, 311) = Huffman 123 ff.].

[...] But since these principles [limiters and unlimited] existed and were neither alike nor even of the same race (or related), it would have been impossible for them to be ordered, if harmony had not come upon them, in whatever way this came to be. What is alike and of the same race (or related) did not in addition require harmony at all, but what is not alike nor of the same race (or related) nor of the same rank, is necessarily bonded together by harmony, if it is going to be held within an order ${ }^{36}$.

I shall now air some possible alternative ways one might think of $\alpha \rho \mu$ oví $\alpha$ as being something other than a power, and argue against them.

One could perhaps think of harmony as a process (rather than a power), namely the process of fitting together. I cannot examine, within the limits of this paper, the metaphysics of process, but I rely on Rescher's ${ }^{37}$ definition. If harmony was a process, and if a process is a complex ("a unity of distinct stages or phases") constituted of other elements (stages or phases) as its building blocks, harmony would then be nonfundamental. But, if harmony were not fundamental, it would be impossible for it to

\footnotetext{
${ }^{35}$ On this idea, see also Philolaos VS 32 B 10 (I, 312) = Huffman (1993), pp. 416 - 417, which

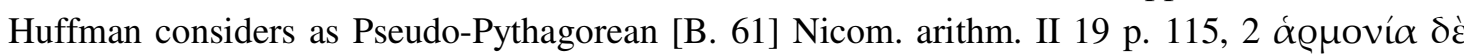

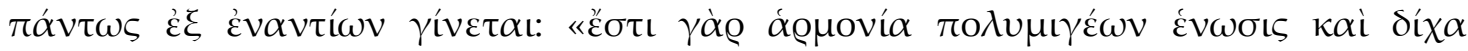

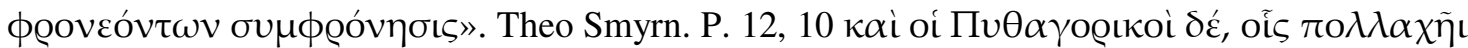

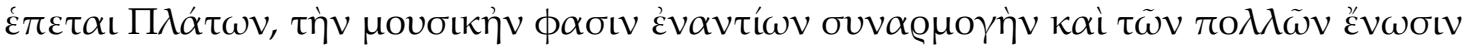

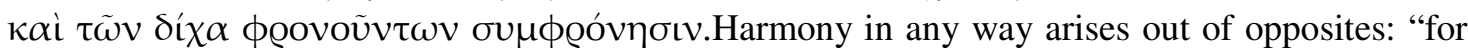
harmony is the unification of what is in mixture of many ingredients and the agreement of the disagreeing. And the Pythagoreans, whom Plato follows in many ways, say that music is the combination of opposites, a unification of many things, and the agreement of the disagreeing (Huffman's translation).

${ }^{36}$ My translation, based upon Huffman's translation, with emphasis added.

${ }^{37}$ Rescher, Nicolas. Process Philosophy (The Stanford Encyclopedia of Philosophy, 2002, http://plato.stanford.edu/entries/process-philosophy/).
} 
Journal of Ancient Philosophy Vol. VI 2012 Issue 2

come upon and bind together (B 6) the fundamental powers to limit and to be limited, which would then underlie it. Thus, harmony cannot be understood as a process.

An alternative interpretation could describe harmony as the state that results from the fitting together. However, if harmony were a result, there should be something else, other than harmony, which would do the metaphysical job of fitting together. But this idea comes in contrast with the fragment quoted above, according to which it is harmony that binds limiters and unlimiteds together. Second, if harmony were a result, it would be non-fundamental. As in the previous assumption, if harmony were not fundamental, it would be impossible for it to come upon and bind together the fundamental powers to limit and to be limited, which would then underlie it. Thus, harmony cannot be understood as a result.

In what follows, I shall argue that $\alpha \varrho \mu$ oví $\alpha$ is to be essentially understood as a power, namely the power of fitting [two other fundamental powers] together.

In the same fragment B 6, Philolaus seems to identify $\alpha$ Quoví $\alpha$ with number, when, after having introduced the concept of harmony, he immediately goes further, defining it

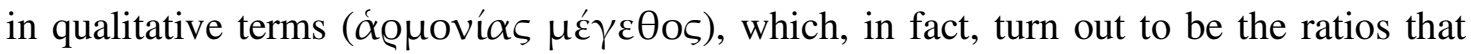
determine the diatonic scale.

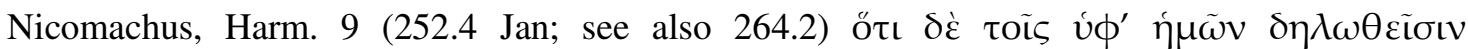

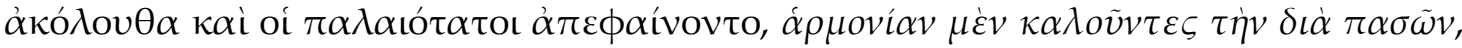

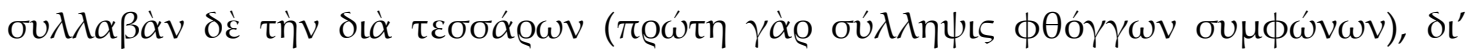

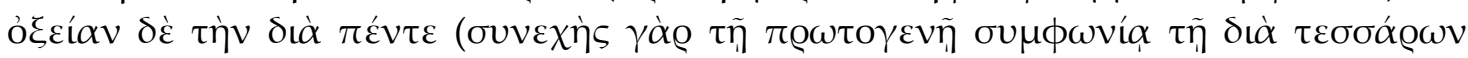

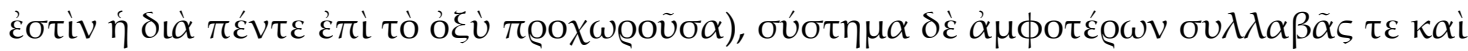

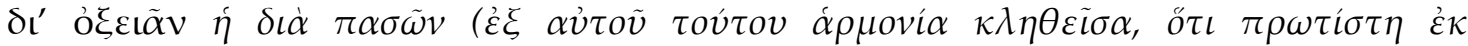

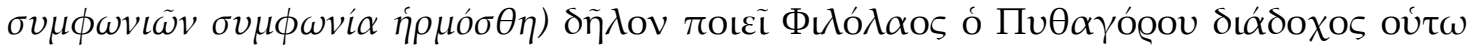

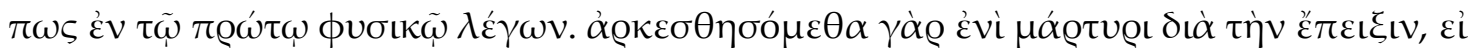

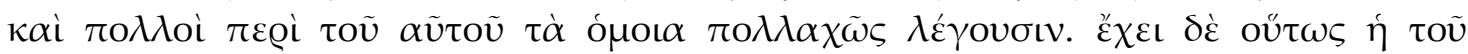

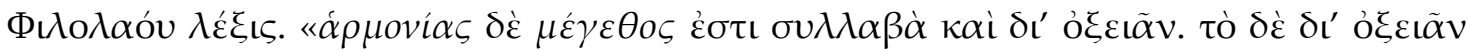

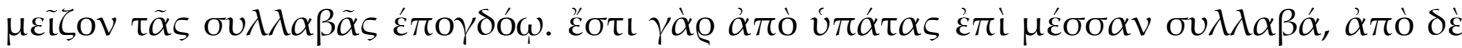

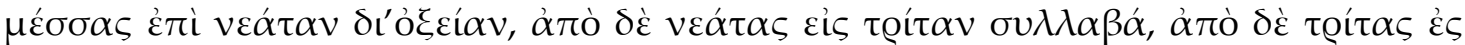

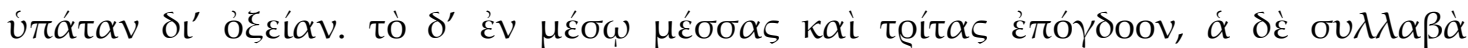

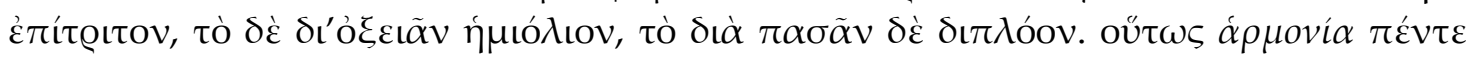


Journal of Ancient Philosophy Vol. VI 2012 Issue 2

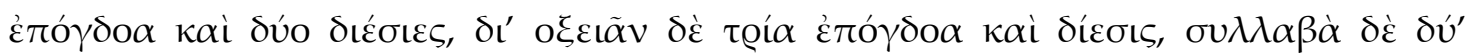

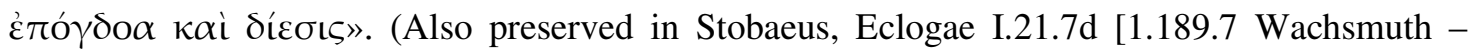
missing in Stobaeus P]). [VS 32 B 6 (I, 311, 10 - 312, 4) = Huffman 145 ff.].

The most ancient thinkers also proclaimed things that are consistent with what I have set forth. They call the octave harmonia, the fourth syllaba (for it is the first grasp [syllepsis] of concordant notes), the fifth dioxeion (for the fifth is continuous with the first concord to be generated, the fourth, and advances to what is higher [to oxy]), and the octave is the composite of both the syllaba [fourth] and dioxeion [fifth] (for this very reason being called harmonia, because it was the first concord fitted together [harmosthe] from concords). Philolaus, the successor of Pythagoras, makes this clear when he says something like the following in the first book of $O n$ Nature. For we will be content with one witness in order to get on with things, even if there are many who in many ways say similar things about this same topic. The text of Philolaus is as follows: "The magnitude of harmonia is the fourth (syllaba) and the fifth (di'oxeian). The fifth is greater than the fourth by the ratio $9: 8$ [a tone]. For from hypate [lowest tone] to the middle string (mese) is a fourth, and from the middle string to neate [highest tone] is a fifth, but from neate to the third string is a fourth, and from the third sting to hypate is a fifth. That which is in between the third string and the middle string is the ratio $9: 8$ [a tone], the fourth has the ration 4 $: 3$, the fifth $3: 2$, and the octave (dia pason) $2: 1$. Thus the harmonia is five $9: 8$ ratios [tones] and two dieses [smaller semitones]. The fifth is three $9: 8$ ratios [tones] and a diesis, and the forth two $9: 8$ ratios [tones] and a diesis ${ }^{38}$.

A@uoví $\alpha$ is thus proportion and number. For Philolaus, number has an epistemological role. Having three distinct kinds, namely even, odd and even-odd ${ }^{39}$, number makes the knowledge of the ćov $\tau \alpha$ (limiting, unlimited and both limiting and unlimited things) possible.

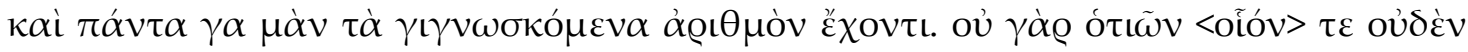

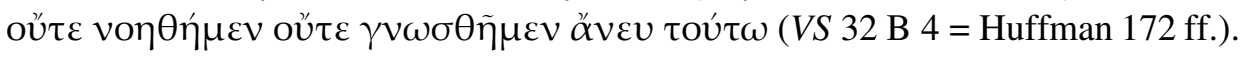

And indeed all the things that are known have number. For it is not possible that anything whatsoever be understood or known without this.

\footnotetext{
${ }^{38}$ Huffman's translation, with emphasis added.

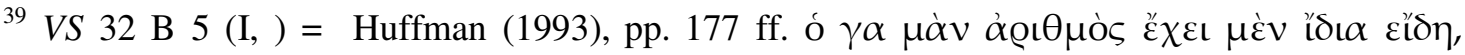

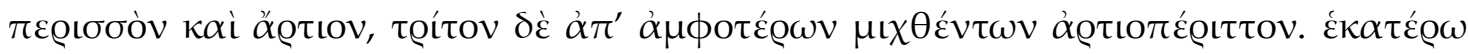

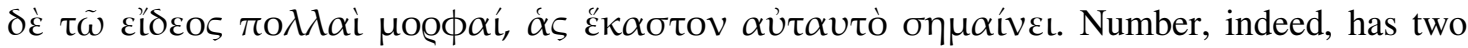
proper kinds, odd and even, and a third from both mixted together, the even-odd. Of each of the two kinds, there are many forms, of which each kind itself gives signs (my translation based upon Huffman's translation).
} 
Journal of Ancient Philosophy Vol. VI 2012 Issue 2

"Having a number" is necessary for something to be an object of knowledge. Nussbaum ${ }^{40}$ takes "number" as roughly equivalent to "limit". But, as mentioned above, Philolaus' fragments keep number quite separate from limiters and unlimiteds. In addition, if Philolaus meant number to be equivalent to limit, there would have been no reason for him to introduce the concept of number at all.

The primary Greek concept of number refers to a concrete ordered plurality ${ }^{41}$. Thus, in the simplest sense, "having number" means being an ordered plurality which is countable. In this light, according to Schofield, Philolaus probably means that "if things are not countable we cannot think of them nor be acquainted with them"42.

However, many examples in Greek thought show that the concept of number refers to something far more complex than an "ordered plurality",43. Burkert ${ }^{44}$ seems to approve this view when he suggests that "having number" means being involved in some kind of numerical relationship. Huffman's ${ }^{45}$ interpretation is more subtle: "having number" is equivalent to having a structure which can be described in mathematical terms. Thus, the knowledge of a thing consists in the knowledge of its mathematical structure. More precisely, Huffman asserts that Philolaus' thought is that

"We only know things by grasping the numerical structure according to which the limiters and unlimiteds which compose them are combined" ${ }^{46}$.

\footnotetext{
${ }^{40}$ Nussbaum (1979), p. 92.

${ }^{41}$ See the studies of Stenzel, Julius. Zahl und Gestalt bei Platon und Aristoteles (Leipzig, 1933; repr. Darmstadt, 1959), pp. 25 ff., and Becker, Oskar. Zwei Untersuchungen zur antiken Logik (Wiesbaden, 1957), pp. $21 \mathrm{ff}$.

${ }^{42}$ Schofield (1983), p. 327.

${ }^{43}$ See for example Aristotle, De Caelo, I, 268 a 10 - 13; Hippocrates, De Generatione, 7, 484 L.

${ }^{44}$ Burkert (1972), p. 267.

${ }^{45}$ Huffman (1993), pp. 70 ff.; 175.

${ }^{46}$ Ibid., pp. 74 .
} 
Journal of Ancient Philosophy Vol. VI 2012 Issue 2

On the interpretation I want to propose, Philolaus' thought is that we only know things by grasping the numerical structure according to which the power to limit and the power to be limited are fitted together to form a thing which is limiting or unlimited or both limiting and unlimited. On my reading, postulating harmony as a third principle which binds limiters and unlimiteds together, Philolaus considers that things not only are known or understood because of number, but also that things are what they are because of number and proportion, which is harmony. If it is impossible for a thing to be known without number, this is because it is impossible for a thing to be what it is without number: it is number, which, along with the basic powers to limit and to be limited (epistemologically secondary in comparison to number), which makes things what they are. In order to be acquainted with things, we must first be acquainted with the number that defines their nature (that is, the proportion according to which limiters and unlimiteds are fitted together).

Thus, I submit that number has a precise metaphysical role in Philolaus' system, and that this role is to be understood in close connection to the role of harmony, the third principle without which it would have been impossible for limiters and unlimiteds to be fitted together ${ }^{47}$.

Philolaus is clearly part of the Pythagorean tradition, which tries to prove certain properties of numbers. It seems that it was a common assertion of Pythagorean ontology to think of number as equated to a power ( $\delta \dot{v} v \alpha \mu \iota \varsigma)$. This idea is found in B 11, quoted below:

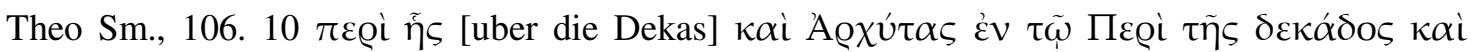

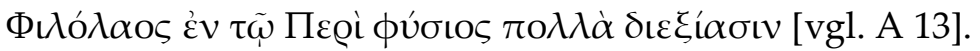

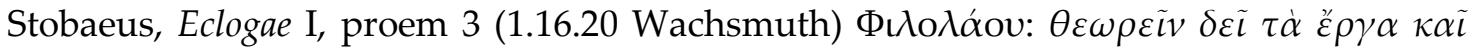

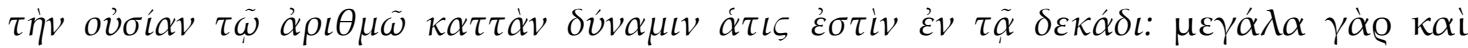

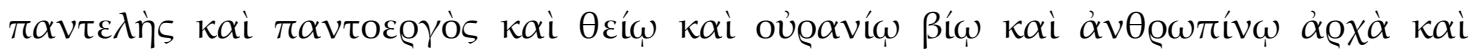

${ }^{47}$ It seems clear to me that Huffman is not right, when he suggests that "Philolaus is perfectly able to talk and think about the world with no mention of number"; ibid., pp. 69. 
Journal of Ancient Philosophy Vol. VI 2012 Issue 2

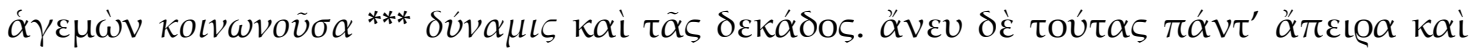

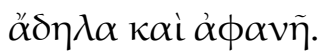

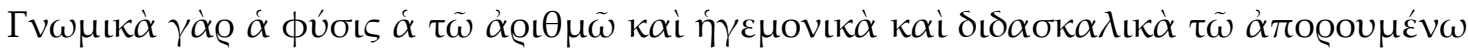

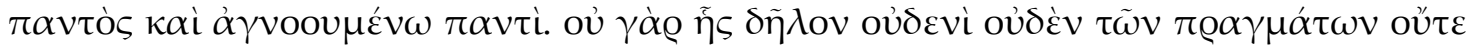

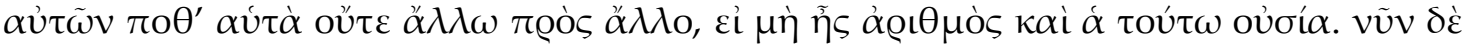

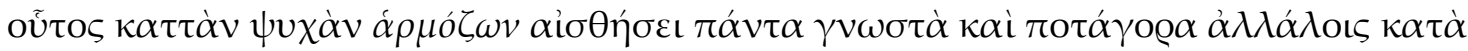

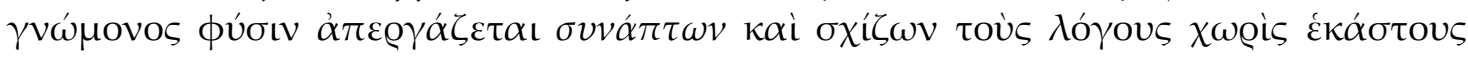

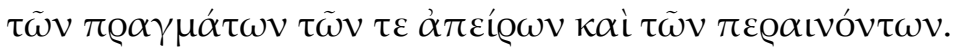

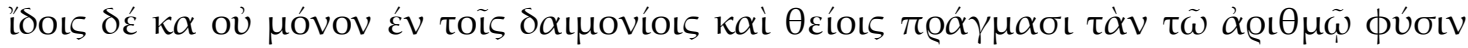

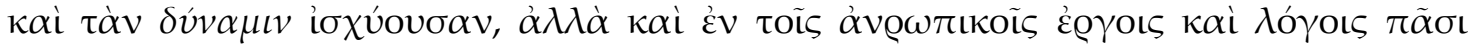

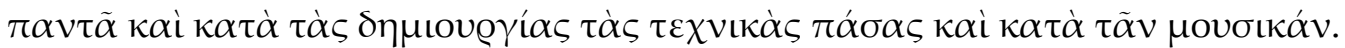

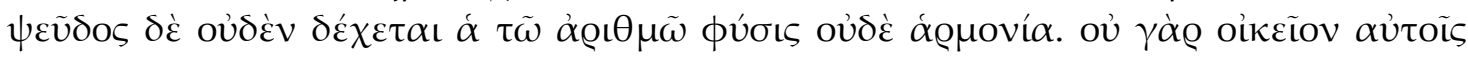

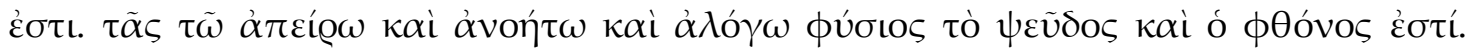

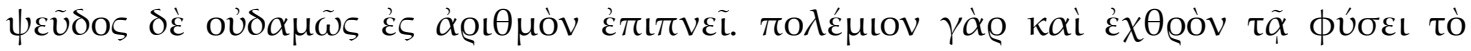

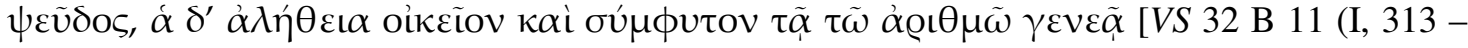
314) = Huffman 347 ff.].

Concerning which [the decad] both Archytas in On the Decad and Philolaos in On Nature expound many things.

One must consider the works and the essence of number according to the power which is in the decad. For it is great, all-complete, and all-accomplishing, the first principle of both divine and heavenly life and also of human life. Taking part *** power also of the decad. Without this all things are unlimited, unclear and uncertain.

For the nature of number is knowledge-giving, authoritative, and instructive for everyone in every case in which they are perplexed or ignorant. For none of the existing things would be clear to anyone either in relation to themselves or in relation to one another, if number and its essence did not exist. But as it is, number in the soul, fitting together all things with perception, makes them known and agreeable with one another according to the nature of gnomon, fixing and loosing the proportions of things, each separately, both of unlimited things and of limiting things.

It is not only in supernatural and divine matters that you can see the nature of number and its power prevailing, but also everywhere in all human deeds and words, both in all the arts of the craftsman and in music.

The nature of number and harmony do not admit of anything false. For it is not akin to them. Falsehood and envy belong to what is unlimited, unintelligible, and irrational ${ }^{48}$. Falsehood in no way breathes upon [or "falls upon"?] number. For falsehood is inimical and hostile to its nature, but truth is of the same family and naturally tied to the race of number.

${ }^{48}$ Huffman's translation. 
Journal of Ancient Philosophy Vol. VI 2012 Issue 2

The notion of $\delta \dot{v} v \alpha \mu \iota \varsigma$ related to number appears again in a later passage referring to Pythagorean number doctrine. According to the source of Aetius, the number ten, which the Pythagoreans considered as the nature of number itself, is thought of as powerful:

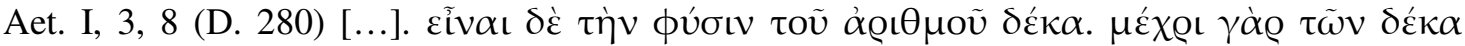

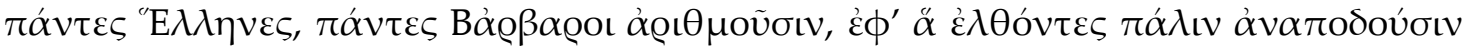

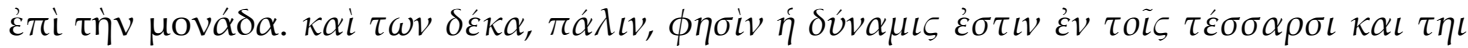

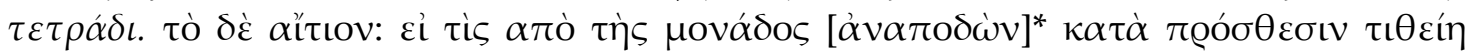

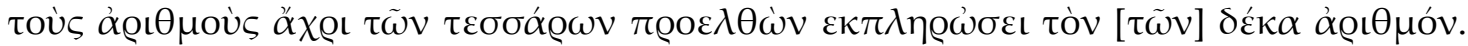

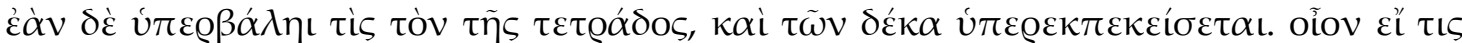

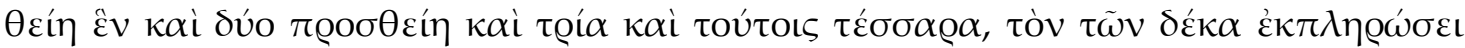

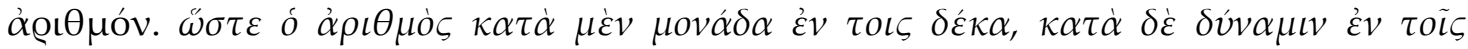

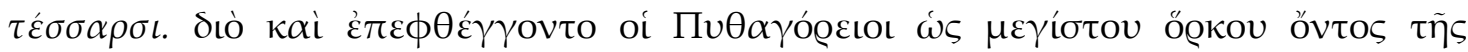

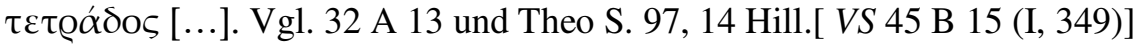

[...]. And the nature of number is ten. Because all Greeks and all non-Greeks count up to ten, and, when they reach it, revert again to unity. And, again, he says that the power of ten is in the four and in the tetrad. The reason for this is the following: if someone starts from the monad and proceeds by adding the numbers up to four, he will reach number ten. But if he goes further than the tetrad, he will also reach further than ten. That is, if one adds one and two, and three, and, to these, four, he will reach number ten. Thus, in relation to (concerning) the monad, the number is in the ten, but, in relation to (concerning) power, the number is in the four. This is why Pythagoreans affirmed that the oath taken on the tetrad is a great oath $[\ldots]^{49}$.

Even if B 11 is spurious and without apparent connection to what Philolaus says in the authentic fragments, as Burkert ${ }^{50}$ and Huffman argue, it still suggests that, for the Pythagorean tradition with which Philolaus is associated, number is to be thought of as

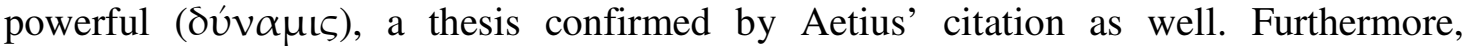
fragment B 11, which could belong to a "modernized" later edition of Philolaus' book, as Burkert $^{51}$ submits, seems to consider this power as a power of connecting

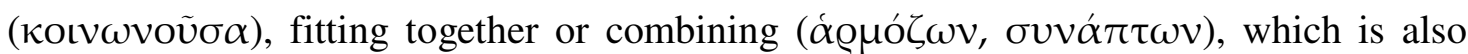
the function of $\alpha \varrho \mu$ ovía.

\footnotetext{
${ }^{49}$ My translation.

${ }^{50}$ Burkert (1972), pp. $273-275$.

${ }^{51}$ Ibid., p. 275, n. 181.
} 
Journal of Ancient Philosophy Vol. VI 2012 Issue 2

In the light of the above considerations, namely that harmony cannot be understood as a process or as a result; that it is equated to number; and that number appears to be considered as powerful, I understand $\alpha \varrho \mu$ oví $\alpha$ as a power ${ }^{52}$, namely the power to join [other fundamental powers] together according to a numeric ratio.

In B 1 , the action of $\alpha \varrho \mu o v i ́ \alpha$ ( $\alpha \varrho \mu o ́ \chi \theta \eta)$ is referred to together with $\phi \dot{\sigma} \sigma \iota \varsigma$ :

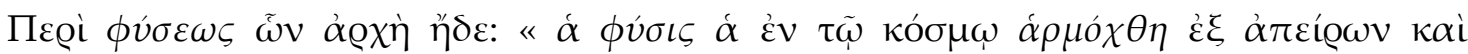

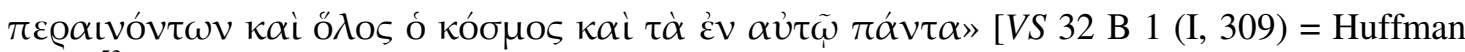
$93 \mathrm{ff}.]^{53}$.

Regarding Philolaus' conception of $\phi v ́ \sigma \iota \varsigma$, there is clear background in Pre- Socratic thought. In fact, as Huffman observes,

"Philolaus' use of pv́бıৎ in the very first line of his book puts him directly in the main line of the Presocratic tradition" $"$.

Holwerda's ${ }^{55}$ and Burket's ${ }^{56}$ assertion that vvoıৎ in B 1 means the totality of the

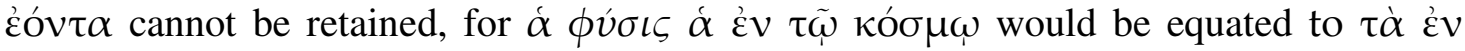
$\alpha \hat{v} \tau \tilde{\omega} \pi \alpha \dot{v} \tau \tau \alpha$, making the sentence unbearably redundant ${ }^{57}$.

It is not my aim here to discuss the Pre-Socratic meaning of "nature" nor is it possible to examine this matter in a satisfactory way within the limits of the present

\footnotetext{
${ }^{52}$ Scoon considers $\alpha$ Q $\mu$ oví $\alpha$ to be a "regulating force", attributing thus to harmony a dynamic meaning; see Scoon, Robert. "Philolaus Fragment 6 Diels", Classical Philology 17, 1922, p. 354.

${ }^{53}$ Emphasis added.

${ }^{54}$ Huffman (1993), p. 96.

${ }^{55}$ Holwerda, Douwe. Commentatio de vocis quae est $\Phi Y \Sigma I \Sigma$ vi atque usu praesertim in graecitate Aristotele anteriore (Groningen, 1955), p.78.

${ }^{56}$ Burkert (1972), p. 250, n. 58; 274.

${ }^{57}$ For this argument contra Holwerda and Burket, see also Huffman (1993), p. 97.
} 
Journal of Ancient Philosophy Vol. VI 2012 Issue 2

paper $^{58}$. However, it is necessary to refer to it, in order to have a complete account of what Philolaus thinks.

Concerning the fundamental and etymological meaning of $\phi v ́ \sigma \iota \varsigma$, Naddaf, whose explanations I endorse, writes:

"If one considers that all the compounds of the term phusis and its corresponding verb phuôphuomai conserve the primary meaning of "growth, growing" throughout antiquity (and, in particular, in the context of vegetation), then it seems clear the fundamental and etymological meaning of the term phusis is that of growth, even if the meaning of the term evolved. It therefore follows from a linguistic analysis of the word that, as an action noun ending in -sis, phusis means the whole process of growth of a thing from birth to maturity" 59 .

This is clearly a dynamic meaning:

"Phusis must be understood dynamically as the real constitution of a thing as it is realized from beginning to end with all of its properties. This is the meaning one finds nearly every time the term phusis is employed in the writings of the pre-Socratics. It is never employed in the sense of something static, although the accent may be on either the phusis as origin, the phusis as process, or the phusis as result. All three, of course, are comprised in the original meaning of the word phusis" ${ }^{60}$.

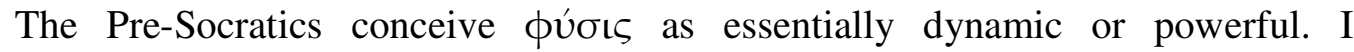
tentatively suggest that the most helpful way of thinking of it is as a power, namely, the power to grow/ to develop/ to produce; a power which can go through infinitely different stages of realization. The Pre-Socratic $\phi u ́ \sigma \iota \varsigma$ is a power perpetually realized by a transition to a different status of itself.

The other powers in the world are derivative and grounded on this ever-realized power. This claim could be spelled out in various ways. However, these conclusions are undoubtedly very tentative, and saying more on this topic goes beyond the scope of the present paper.

\footnotetext{
${ }^{58}$ This question should be examined in a monograph.

${ }^{59}$ Naddaf, Gerald. The Greek Concept of Nature (New York: State University of New York Press, 2005), p. 12.

${ }^{60}$ Ibid., pp. 15 .
} 
Journal of Ancient Philosophy Vol. VI 2012 Issue 2

Nevertheless, to the extent Philolaus is aligned with the Pre-Socratic tradition, the

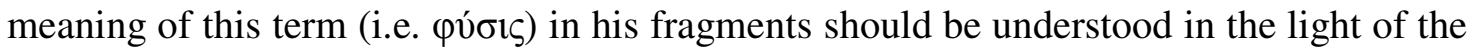

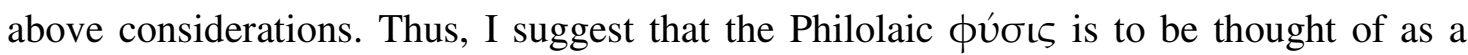
power with infinite different stages of realization within itself.

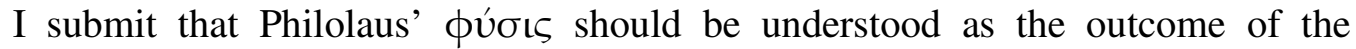
working of the three other powers, namely $\pi \varepsilon \varrho \alpha i ́ v o v \tau \alpha, \alpha$ $\pi \varepsilon \iota \alpha$ and $\alpha \varrho \mu o v i ́ \alpha$ coming together and coming to be realized ( $\dot{\alpha} \varrho \mu$ ó $\chi \theta \eta)$. In other words, $\varphi v ́ \sigma ı \varsigma$ is the state that results from the realization of the three fundamental powers.

I have so far discussed Philolaus' four primary powers, namely $\pi \varepsilon Q \alpha i ́ v o v \tau \alpha$,

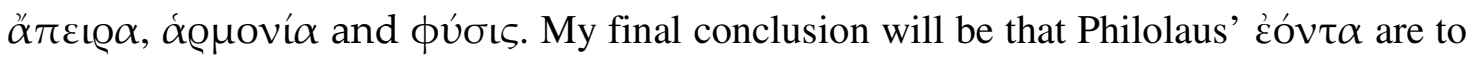
be considered as coming out of the four primary powers and of what Philolaus refers to as $\dot{\varepsilon} \sigma \tau \dot{\omega}$. What $\dot{\varepsilon} \sigma \tau \omega$ exactly is, is another interpretative challenge, which I shall briefly try to tackle here.

'E $\sigma \tau \omega$ is mentioned in B 6, perhaps the most interesting of Philolaus' fragments, along with $\varphi v ́ \sigma ı \varsigma$ and $\alpha \varrho \mu o v i ́ \alpha$ :

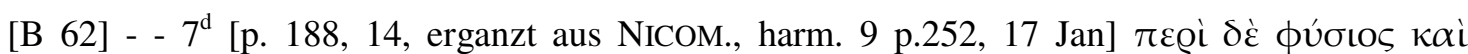

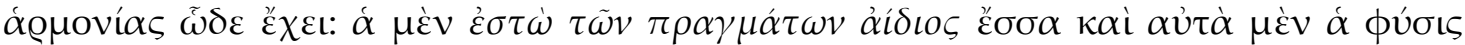

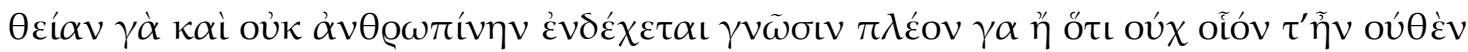

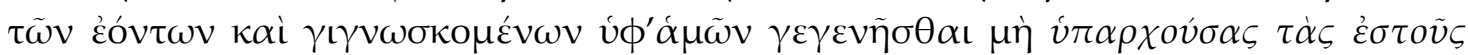

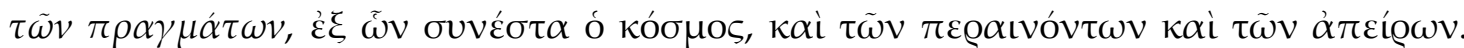
[VS 32 B $6(\mathrm{I}, 310)=$ Huffman $123 \mathrm{ff}$.]

Concerning nature and harmony, the situation is this: the $\dot{\varepsilon} \sigma \tau \dot{\omega}$ of things, which is eternal, and nature itself admit of divine and not human knowledge, except that it was impossible for any of the "things that are (in the present time)" and are known by us to have come to be, if the $\dot{\varepsilon} \sigma \tau \dot{\omega}$ of the things from which the world-order was constituted, both [of] the limiting [things] and [of] the unlimited [things], did not exist ${ }^{61}$.

${ }^{61}$ My translation based upon Huffman's translation. 
Journal of Ancient Philosophy Vol. VI 2012 Issue 2

It is difficult to know what $\dot{\varepsilon} \sigma \tau \omega$ exactly means. Burkert suggests that it may be an ionic formation ${ }^{62}$. Except for this fragment, the term is only found in the later Pythagorean tradition, where it is however very rare. Iamblichus cites $\dot{\varepsilon} \sigma \tau \hat{\omega}$ as one of

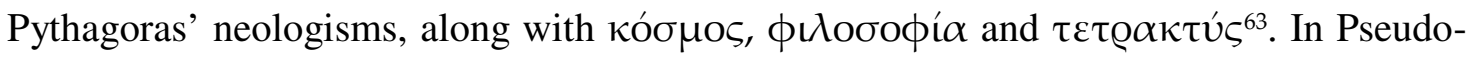
Archytas, where the same expression, $\dot{\varepsilon} \sigma \tau \dot{\omega} \tau \tilde{\omega} \nu \pi \varrho \alpha \gamma \mu \alpha \dot{\alpha} \tau \omega \nu$, is found, $\dot{\varepsilon} \sigma \tau \dot{\omega}$ is used in the sense of Aristotelian matter ${ }^{64}$. Bywater ${ }^{65}$ and Scoon $^{66}$ argue that $\dot{\varepsilon} \sigma \tau \omega$ is used in the same sense in B 6. The latter concludes:

"If Philolaus took over the elements, $\dot{\varepsilon} \sigma \tau \omega$ in the present passage would signify the material substance of the world, existing as earth, air, fire and water" ${ }^{67}$.

Schofield ${ }^{68}$ understands it as "the real being of things, which - following the Eleatics - Philolaus takes to be everlasting”. Similarly, Burkert ${ }^{69}$ takes $\dot{\varepsilon} \sigma \tau \grave{\omega}$ to be the "everlasting being of things", considered in an Eleatic way. Barnes ${ }^{70}$ supposes that the phrase "the $\dot{\varepsilon} \sigma \tau \grave{\omega}$ of things" must mean something like "the existents par excellence". According to Huffman ${ }^{71}$, $\dot{\varepsilon} \sigma \tau \grave{\omega}$ "represents a fused notion of existence and essence", and the only thing we are said to know about it is that it preexists (vं $\pi \dot{\rho} \rho \chi \varepsilon v$ ).

\footnotetext{
${ }^{62}$ Burkert (1972), pp. 256.

${ }^{63}$ Iamblichus, Vita Pythagoris, 162.

${ }^{64}$ Thesleff, Holger.. Pythagorean Texts of the Hellenistic Period. Acta Academiae Aboensis, Humaniora 1965, 30.1, pp. 19 ff.

${ }^{65}$ Bywater, Ingram. "On the fragments attributed to Philolaus the Pythagorean", Journal of Philology, 1, 1868, p. 34.

${ }^{66}$ Scoon (1922), p. 354.

${ }^{67}$ Ibid.

${ }^{68}$ Schofield (1983), pp. $327-328$.

${ }^{69}$ Burkert (1972), pp. $256-257$.

${ }^{70}$ Barnes (1979), p. 83.

${ }^{71}$ Huffman (1993), pp. $130-132$.
} 
Journal of Ancient Philosophy Vol. VI 2012 Issue 2

Any of these interpretations appears to be compatible with the main claim this paper is arguing for, that is, the claim that the fundamental entities in Philolaus' ontology are powers.

Thus, Philolaus appears to be one of the first power structuralists in the history of philosophy.

Irini - Fotini Viltanioti

University of Oxford / FRS - FNRS / ULB

References

Barnes, Jonathan. The Presocratic Philosophers (London, 1979).

Becker, Oskar. Zwei Untersuchungen zur antiken Logik (Wiesbaden, 1957).

Bird, Alexander. Nature's Metaphysicis: Laws and Properties (Oxford, Oxford University Press, 2007).

Boeckh, August. Philolaos des Pythagoreers Lehren nebst den Bruchstucken seines Werkes (Berlin, 1819).

Burkert, Walter. Lore and Science in Ancient Pythagoreanism (Cambridge, Mass, 1972); English translation of: Weisheit und Wissenschaft: Studien zu Pythagoras, Philolaos und Platon (Nurenmberg, 1962).

Bywater, Ingram. "On the fragments attributed to Philolaus the Pythagorean", Journal of Philology, 1, 1868, pp. $21-53$.

Cherniss, Harold. "The Characteristics and Effects of Presocratic Philosophy", Journal of the History of Ideas, 1951, 12, 319 - 345.

Cherniss, Harold. Aristotle's Criticism of Presocratic Philosophy (Baltimore: John Kopkins Press, 1935; repr.: New York: Octagon, 1964). 
Journal of Ancient Philosophy Vol. VI 2012 Issue 2

Choi, Sungho and Fara, Michael. Dispositions (The Stanford Encyclopedia of Philosophy, 2012, http://plato.stanford.edu/entries/dispositions/).

Guthrie, William Keith Chambers. A History of Greek Philosophy (Cambridge, 1962).

Heil, John. From an Ontological Point of View (Oxford, Clarendon Press, 2003).

Holwerda, Douwe. Commentatio de vocis quae est $\Phi Y \Sigma I \Sigma$ vi atque usu praesertim in graecitate Aristotele anteriore (Groningen, 1955).

Huffman, Carl. Philolaus of Croton. Pythagorean and Presocratic. A commentary on the fragments and testimonia with interpretative essays (Cambridge: Cambridge University Press, 1993).

Hussey, Edward. "Pythagoreans and Eleatics", in Taylor, Christopher (ed.). From the Beginning to Plato, Routledge History of Philosophy I (London and New York, 1997), pp. $128-174$.

Kirk, Geoffrey Stephen. Heraclitus. The cosmic fragments (Cambridge: Cambridge University Press, 1954).

Marmodoro, Anna. "Do Powers Need Powers to Make Them Powerful? From Pandispositionalism to Aristotle", History of Philosophy Quaterly, 26, 2009, pp. 337 352.

Martin, Charles Burton. The Mind in Nature (Oxford, Oxford University Press, 2008).

Mumford, Stephen. Dispositions (Oxford University Press, 1998).

Mumford, Stephen and Anjum, Rani Lill. Getting Causes from Powers (Oxford, Oxford University Press, 2011).

Naddaf, Gerald. The Greek Concept of Nature (New York: State University of New York Press, 2005).

Nussbaum, Martha. "Eleatic conventionalism and Philolaus on the conditions of thought", Harvard Studies in Classical Philology, 83, 1979, 63 - 108.

Raven, John Earle. Pythagoreans and Eleatics (Cambridge, Cambridge University Press, 1948).

Nicolas, Rescher. Process Philosophy (The Stanford Encyclopedia of Philosophy, 2002, http://plato.stanford.edu/entries/process-philosophy/).

Kirk, Geoffrey Stephen and Raven, John Earle, The Presocratic Philosophers, (Cambridge, Cambridge University Press, 1957); $2^{\text {nd }}$ ed. revised by Schofield, Malcolm (Cambridge: Cambridge University Press, 1983).

Scoon, Robert. "Philolaus Fragment 6 Diels", Classical Philology 17, 1922, pp. 353 356. 
Journal of Ancient Philosophy Vol. VI 2012 Issue 2

Stenzel, Julius. Zahl und Gestalt bei Platon und Aristoteles (Leipzig, 1933; repr. Darmstadt, 1959).

Thesleff, Holger.. Pythagorean Texts of the Hellenistic Period. Acta Academiae Aboensis, Humaniora 1965, 30.1.

Verdenius, Jas Hendrik Waszink. "Notes on the Presocratics", Mnemosyne s. 3. 13, 1947, pp. 271 - 289.West, Martin Litchfield. Early Greek Philosophy and the Orient (Oxford, Oxford University Press, 1971). 